\title{
Indonesian two-week fieldwork in Australia: Great or no impact?
}

\author{
Anita Sartika Dewi \\ Islamic University of Yogyakarta
}

\begin{abstract}
This paper is a sociolinguistic study on the impact of a two-week fieldwork experienced by English Diploma Program students of Universitas Islam Indonesia (UII) Yogyakarta in Australia. The aspects to be scrutinized are the effect of the program on the students' self development and their understanding of Australia, and how their retum to Indonesia influences their fellow students at the Islamic university.

Impact of the two-week fieldwork is seen from two theoretical backgrounds language perception. (Lowe, 2000) and orientation (Gardner, 1985). Data collection was carried out through email questionnaires. Several themes occurred were expectation on the fieldwork, expectation on life in Australia, family expectation, reality faced in Australia, most meaningful experiences, and returning to Indonesia.

Results of the study show that the fieldwork has brought an "instrumentally oriented" impact on the students' self development and understanding of Australia. Even though the students gained more than previously expected, more could have been achieved as there was no strong influence on other UII students, yet.

Keywords: sociolinguistic study, fieldwork experience, language perception, orientation.
\end{abstract}

\section{Introduction}

There are three main areas in which Indonesian higher educational institutions are required to play roles in learning and teaching activities, research, and social service. Incorporating the three, fieldwork is a crucial element in the 
education process where students are faced with real life situations which they might encounter in their future. This paper is aimed at scrutinising the impact of a two-week fieldwork experienced by Indonesian Islamic tertiary students in Australia from the perspective of sociolinguistics.

The Indonesian students investigated are students of English Diploma Program at Universitas Islam Indonesia (UII) Yogyakarta. These fieldwork participants were selected among many other students of this department based on merit, who were then provided with either full or partial grants to experience a twoweek fieldwork in Australia. Their ages range from 18 to 26 years old and they. come from both rural and urban areas of Indonesia. This particular study covers three batches of fieldwork that have been carried out, from 2007 to 2009 .

The paper focuses on Indonesian Islamic students because of some considerations. First of all, Indonesia is the fourth most populated country in the world, which makes it a potentially significant country. It is furthermore the largest Muslim community across the globe (Library of Congress, 2004), which consists of approximately 35 ethnic groups and 725 languages and dialects where 500 of them are mutually unintelligible (Dardjowidjojo, 2000). Being the largest Muslim community, however, the flavour of Islamic community in Indonesia is unlike that of Middle East or any other areas in the world. Indeed, as suggested by Dan et al., local and/or national cultures are embedded in the spread of Islam (Dan, Haroon, \& Naysmith, 1996). This becomes a strong rationale for conducting this study of Indonesian Islamic students.

3esides being complicated in itself with diverse local values, Indonesia has been a long-time neighbour of Australia. The relationship between these two countries has gone through 'roller-coaster'-like movements. The intimate and nonintimate, ups and downs, and many other way of expressing the relationship between the two countries describe the dynamics of it. Governments of both countries have been trying to collaborate in various ways. In fact, the topic brought forward in this paper is very much in line with a bilateral agreement signed by the President of the Republic of Indonesia and the Prime Minister of Australia in 2005. It is stated in the agreement that "The people-to-people links between Australians and Indonesians are the foundation of our relationship. We want to encourage and strengthen these links, in both directions. Education links are central to this." (Indonesia \& Australia, 2005) 
As a realisation of educational 'people-to-people links', the fieldwork is conducted under a Memorandum of Understanding (MoU) between Universitas Islam Indonesia Yogyakarta and two Australian secondary colleges in Mornington-Peninsula area. The first batch was carried out when strict travel arrangement due to issue of terrorism was applied by Australian government in 2007. This travel advisory, however, has not been a serious issue constraining the conduct of fieldwork. The proof of it is the continued fieldwork to its second and third batches in 2008 and 2009 , respectively.

As mentioned above, the fieldwork was initiated under a Memorandum of Understanding between an Indonesian university and two Australian secondary colleges. The fieldwork is in fact a proof of a successful independent initiative of a "U to Ss" (university to schools) cooperation, instead of a commonly " $U$ to $U$ " (university to university) or "sister schools" (between schools) scheme. As an independent initiative, travel grants for participants have been provided by Universitas Islam Indonesia (UII), while accommodation for them has been sponsored by voluntary host families. This is the main reason for conducting the fieldwork in no more than two week period, as it would be too much burden for both UII and the host families.

\section{Study Objective}

As already mentioned in the introduction section, the main aim of this study is to investigate the impact of the two-week fieldwork from sociolinguistic perspective. Specifically, the sociolinguistic aspects that are tried to be scrutinized are:

1. The effect of the program on the students' self development and their understanding of Australia

2. How their return to Indonesia influences their fellow students at the Islamic university

\section{Discussion}

In the sociolinguistic viewpoint, impact of the two-week fieldwork is seen from two theoretical backgrounds language perception and orientation. In Longman's Dictionary of Language Teaching and Applied Linguistics, perception 
is defined as "the recognition and understanding of events, objects, and stimuli through the use of senses" (Richards \& Schmidt, 2002, p. 391). Therefore, perception involves interactions between one and objects and/or situations around $\mathrm{him} /$ her. In reality, as asserted by Lowe (2000, p. 138), perception is contextual, so that perception of an object involves its surrounding.

Through email questionnaires with the participants, some sections occur as results of the sociolinguistic study. The first section is expectation on the fieldwork itself, followed by the expectation on life in Australia, family expectation, reality faced in Australia, most meaningful experiences, and returning to Indonesia.

In expectation of the fieldwork, the participants mainly elaborate matters related to new experience, English language improvement, and activities that they prepared prior to leaving for Australia. This can be seen from the following responses of participants' expectation on the fieldwork:

- "...never been overseas before"

- "...stand in front of many students explaining stuff like culture, handycraft, Islam, and many more."

- "...tour deAussie."

- "...know and learn in the country that uses English."

- "Giving information and discussing all about Indonesia."

- "...have more experience with foreign people."

- " "...try something new, to enrich my experience."

- "I could improve my English."

- "I could increase my capability my English and it's one of my greatest experience in life."

- "I had to explain the material that I had prepared before (presentation)."

In expectation of life section, it was found that there are three main themes, namely the situation, the daily life, and the people that they expected to meet. This is shown in examples of responses below:

1. Situation:

- “...see many cars, huge building, a sight of big city just like in western movie."

- "Everything is well-organized." 
2. Daily life:

- “...good public facilities in Aussie(West Country)."

- "...live with foreign people.".

- "...it would be so difficult to stand the culture, to live in a place where I don't even know anyone."

- "...so difficult to live in very different culture."

- "...it would be fun to know different people in different culture."

3. People:

The participant expected that they would meet white, tall, individual, nice, friendly, hi-tech, honest, discipline, and punctual people. There was only one participant anticipated to meet diverse people, as he stated that he expected to meet "nice people and friendly with so many different culture and language"

The abovementioned responses suggest that perception, including perception of a language, is contextual. The fieldwork participants' perceptions are not only that of the language per se, but it involves the surrounding such as the life situation and people.

Following language perception discussed above, orientations of leaming the language occur. These orientations are termed by Gardner as "integrative" and "instrumental" orientations. "Integrative" involves emotion, whereas "instrumental" is more of benefits such as career, education, and occupation (Gardner, 1985, p. 11, 2001, p. 1). Instrumental orientation was clearly shown on the family expectation upon the participants' departure for Australia, as follow:

- "many experiences"

- "English skill improvement"

- "knowledge enrichment"

- "help finding a good job later"

- "get scholarship and continue my study there"

In reality, the facts experienced were very contextual and more than expected. Simplifying them into two aspects daily activities and socialising, the experiences were beyond their expectation. The following are examples of their daily activities they did and how they socialised:

1. Daily activities:

- discussing and presenting about Islam and Indonesian cultures 
- helping students doing their task

- watching and discussing movies related to "hot issue"

- assisting Bahasa Indonesia teachers

- coaching sports, assisting art, cooking, math classes

- teaching Indonesian songs and dance

- discussing about VCE materials ('jamu')

- travelling

- presenting about Islam, Ramadhan month, and traditional game

2. Socialising:

- very good

- helping each other

- easier than in Indonesia

- a little uncomfortable because of headscarf

- individual life style but respectful to each other

Furthermore, the participants' most meaningful experiences could mainly be grouped into student-teacher relationship, cultural understanding, English learning, knowledge enrichment, and people-to-people relationship. This certainly suggests the contextual experiences, which mostly involves instrumental orientation of learning the language. The following are some prominent remarks that the participants elicited about their unforgettable experiences:

1. Student-Teacher relationship:

- "Australian students are active and dare to express what they think"

- "They can have good relationship. Students have enough bravery to say something (agree or disagree) about lesson and teacher respect of it."

- "Being a teacher is not easy as it looks"

2. Culture understanding, which covers family life, school life, and neighbourhood in Australia

3. English learning:

- "practise English everyday"

- "English improvement is not as rapid as expected"

- "capable of speaking in front of many people in another (English speaking) country" 
4. Knowledge enrichment, through their expression of broadening horizon, going through new experiences, and being eager to work or continue study overseas.

5. People to people relationship, both with Australians and among coparticipants of the fieldwork.

Upon their return to Indonesia, the participants shared their experiences with various kinds of people of both close and distance relations. This includes parents, siblings, friends, extended family, and anyone who asks. The last 'person' mentioned anyone who asks, figures the non-active act of the participants to share their experiences.

In terms of family, the responses received by the fieldwork participants were good impressions such as "They are proud of me", "brighter future", "English skill and my experience in Australia to get a good job". Meanwhile, the participants explained how their fellow students "do not underestimate" them and in fact they thought that their "English speaking skill increased". In the broader society, similarly, more expressions of appreciation were received, such as "Wow you are great", "That is amazing", and the feeling of "I am a success".

\section{Conclusion}

Based on the fact found in the investigation, it is clear that the fieldwork has brought an impact on the students' self development and understanding of Australia. The impact, however, has mostly been "instrumentally oriented". What has been achieved is more than expected, but actually there are more that can be achieved, since it is not simply prestige that matters. In the sense of influence on fellow students at the Islamic university, there has not been found any prominent matters.

Considering the findings of the three batch participants of fieldwork, further effort should be carried out to realise a mutually beneficial and meaningful "people-to-people links" (Indonesia \& Australia, 2005). This can be done through provision of a "sharing arena" for PPL returnees, such as clubs and/or discussion forum. Further down the track, development of "both directions" programs, Australia-Indonesia exchange, should be encouraged. Finally, scrutiny must be 
conducted not only on Indonesian students' side, but also on the impact of the fieldwork on Australian students, teachers, and society.

\section{Bibliography}

Dan, W. C., Haroon, H. A., \& Naysmith, J. (1996). English and Islam in Malaysia:

Resolving the tension? World Englishes, 15(2), 225-234.

Dardjowidjojo, S. (200). English teaching in Indonesia. EA Journal, 18(1), 22-30.

Gardner, R. C. (1985). Social psychology and second language learning: The role of attitudes and motivation (Vol. 4). Caulfield East: Edward Amold (Australia) Pty. Ltd.

Gardner, R. C. (2001). Integrative motivation and second language acquisition. In Z. Dornyei \& R. Schmidt (Eds.), Motivation and second language acquisition (pp. 1-20). Honolulu: University of Hawaii Press.

Joint declaration on comprehensive partnership between Australia and the Republic of Indonesia (2005).

Library of Congress, U. S. (December 2004). Indonesia. Country Profile, 1-21. $R$ e $t$ i e v e d f r o m http://memory.loc.gov/frd/cs/profiles/Indonesia.pdfLowe, E. J. (2000). An Introduction to the philosophy of mind. Cambridge: Cambridge University Press. 